\title{
CURSOS E PROFISSÕES: CONHECENDO POSSIBILIDADES PARA A ESCOLHA PROFISSIONAL
}

\author{
Fernanda Zatti \\ Instituto Federal do Rio Grande do Sul \\ fernanda.zatti@erechim.ifrs.edu.br \\ Cristiane Câmara \\ Instituto Federal do Rio Grande do Sul \\ cristiane.camara@erechim.ifrs.edu.br
}

\author{
Régis Nogara dos Reis \\ Instituto Federal do Rio Grande do Sul \\ regis.reis@erechim.ifrs.edu.br \\ Silvia LethiciaFrandolozo \\ Instituto Federal do Rio Grande do Sul \\ silvia.frandolozo@erechim.ifrs.edu.br \\ Larissa Brand Back \\ Instituto Federal do Rio Grande do Sul \\ larissa.back@erechim.ifrs.edu.br
}

\begin{abstract}
Resumo
O trabalho apresenta reflexões sobre um projeto de extensão realizado em um Instituto Federal de Educação, Ciência e Tecnologialocalizado no Rio Grande do Sul. O projeto objetivou fornecer, aos estudantes concluintes do Ensino Médio da rede estadual do município, informações sobre os cursos ofertados pela instituição, visando a auxiliá-los no processo de escolha profissional e reduzir índices de evasão relacionados à falta de conhecimentosobre o curso escolhido. Participaram da ação oito das nove escolas definidas como público-alvo, totalizando 459 estudantes. O projeto oportunizou espaços para reflexão e qualificação do processo de escolha profissional, colocando em pauta cursos, possibilidades de formação e carreiras profissionais. Acredita-se que as ações desenvolvidas ampliaram o conhecimento local da instituição e possibilitaram maior congruência entre as concepções e expectativas dos estudantes e a realidade dos cursos ofertados, favorecendo escolhas mais conscientes e, consequentemente, maior adequação e satisfação com o curso e com a profissão escolhida.
\end{abstract}

Palavras-chave: Formação profissional. Extensão universitária. Escolhas profissionais.

\section{COURSES AND OCCUPATIONS: KNOWING POSSIBILITIES FOR PROFESSIONAL CHOICE}

\begin{abstract}
The study presents reflections about an extension project performed in a Federal Institute of Education, Science and Technology of Rio Grande do Sul. This project aimed to provide graduating high school students from the city's municipalitly schools, information about the courses offered by the institution, in order to assist them in the professional selection process and reduce the dropout rates related to lack of knowledge of the chosen course. This program was attended by eight of the nine schools defined as the target public, totalizing 459 students. The project provides reflection and qualification spaces for the professional selection process, by discussing about courses, training opportunities and professional careers. The actions developed expanded the local knowledge of the institution, allowed greater congruence between the conceptions and expectations of students and the reality of courses offered, encouraging more conscious choices and consequently greater adaptation and satisfaction with the course and the chosen occupation.

Keywords: Professional formation. Academic extension. Occupational choices.

\section{CURSO Y PROFESIONES: CONOCIENDO POSIBILIDADES PARA LA ELECCIÓN PROFESIONAL}

\section{Resumen}

El trabajo presenta reflexiones sobre un proyecto de extensión realizado en un Instituto Federal de Educación, Ciencia y Tecnología localizado en Rio Grande do Sul. El proyecto tuvo como objetivo subministrar a los estudiantes concluyentes de la educación secundaria de la red estadual de la municipalidad informaciones sobre los cursos ofrecidos por la institución, teniendo en vista poder prestar auxilio en el proceso de la elección profesional y reducir índices de evasión relacionada a falta de conocimiento del curso elegido. Participan de la acción ocho de las nueve escuelas definidas como público clave, con una totalidad de 459 estudiantes. El proyecto ofreció espacio para la reflexión y calificación del proceso 
de elección profesional, poniendo en pauta cursos, posibilidades de formación y carreras profesionales. Se cree que las acciones desarrolladas van a ampliar el conocimiento local de la institución y se cree que posibilitarán mayor congruencia entre las concepciones y expectativas de los estudiantes y la realidad de los cursos ofrecidos, favoreciendo elecciones más conscientes y como consecuencia una mayor adecuación y satisfacción con el curso y con la profesión elegida.

Palabras clave: Formación profesional. Extensión universitaria. Elecciones profesionales. 
Cursos e profissões: conhecendo possibilidades para a escolha profissional

\section{INTRODUÇÃO}

A exigência por maior qualificação, principalmente referente ao aspecto da escolaridade, acentua um processo de seletividade por meio do qual os empregadores tendem a dar prioridade à contratação ou manutenção de trabalhadores mais escolarizados em detrimento de outros menos escolarizados, sem que isso represente mudanças no conteúdo dos postos de trabalho e melhor remuneração (JORNADA; SOBRINHO; STENBERG, 2000). Neste âmbito, a formação profissional surge como uma alternativa que pode abrir espaços para a qualificação e a colocação no mercado de trabalho, sendo cada vez mais procurada por jovens que buscam a inserção ou por adultos que almejam a recolocação ou o crescimento profissional.

Assim, a valorização atribuída à qualificação no âmbito da reestruturação produtiva transformou os processos educativos e formativos em elementos de competitividade, fazendo com que houvesse um deslocamento da responsabilidade social para o plano individual, pois já não há políticas de emprego e renda dentro de um projeto de desenvolvimento social, mas indivíduos que devem adquirir competências ou habilidades, nos campos cognitivo, técnico, de gestão e atitudes, para se tornarem competitivos e empregáveis (FRIGOTTTO, 1998).

Conforme Alves e Vieira (1995), as novas exigências de qualificaçãorequeridas pela reestruturação industrial em curso trouxeram a necessidade da correção do rumo das instituições de formação profissional. Para os autores, o processo educacional, seja informal ou formal, não pode ficar alheio aos problemas do emprego, nem pode se restringir a preparar ou capacitar o cidadão para apenas um emprego, mas o processo educativodeve contribuir para o desenvolvimento integral do ser humano, incentivando e educando para a prática da participação individual e coletiva, sendo orientado para aprender a pensar e para o aprender a aprender.

Neste cenário, os Institutos Federais de Educação, Ciência e Tecnologia foram criados com a missão de ofertar educação profissional e tecnológica em todos os níveis e modalidades, objetivando formar e qualificar cidadãos para atuação profissional nos diversos setores da economia, especialmente no que tange ao desenvolvimento socioeconômico local, regional e nacional (Lei no 11.892 de 29 de dezembro de 2008). Dessa maneira, constata-se a importância da criação de estratégias que promovam uma maior aproximação com a comunidade, especialmente quando a instituição é nova no contextoem que está inserida, como é o caso do Campus em que foi desenvolvido o projeto. Entende-se que ações desta natureza são fundamentais para o estabelecimento da instituição de forma a cumprir de modo eficaz sua função social e os objetivos a que se propõe. 
Cursos e profissões: conhecendo possibilidades para a escolha profissional

Ademais, observa-se na comunidade local certo desconhecimento em relação à instituição e aos cursos ofertados, o que por vezes dificulta o acesso. Por outro lado, este mesmo desconhecimento muitas vezes é identificado em relação aos estudantes que ingressam na instituição, gerando dificuldades e resultando no abandono do curso. Este fato pode ser observado nas informações obtidas por meio de um questionário aplicado pela Coordenação de Assistência Estudantil que objetiva conhecer o perfil dos discentes ingressantes. $\mathrm{Na}$ análise dos dados mencionados, é notável o número de discentes que não conhecem a matriz curricular do curso antes de realizar a escolha e, ainda, que poucos conhecem a respeito do campo/demanda de trabalho e da atuação dos profissionais da área. Nesse sentido, percebe-se também,no contato com os estudantes evadidos, que o desconhecimento do curso é um dos fatores apresentados como motivadores da evasão, tanto em cursos técnicos quanto em superiores.

Nesta direção, cabe destacar que a literatura aponta a disponibilidade de informações sobre os cursos e profissões como um dos principais elementos que contribuem para uma escolha profissional acertada (FERRETI, 1988; CARVALHO, 1995; VILELA, 2003). Desse modo, Lassance (1999) salienta que as novas características das relações de trabalho e da constituição do próprio mercado de trabalho, quando as circunscrições das profissões tornam-se maisfluídas, transformaram a escolha profissional em um processo complexo.

Assim sendo, Carvalho (1995) afirma que as informações a respeito dos cursos disponíveis no mercado são questões importantes, pois os jovens podem possuir conhecimento a respeito das profissões mais conhecidas e de maior sstatus social em função das contingências, deixando de conhecer as que lhes oferecem, ou que podem oferecer maior satisfação pessoal. Conforme o autor, no processo de escolha profissional há determinantes psíquicos, sociais e econômicos que podematuar ao mesmo tempo, de modo que a posição social é o determinante mais relevante, assim como as oportunidades locais, educacionais ou ocupacionais e as condições socioeconômicas existentes também influenciam no processo de escolha.

Neste contexto, a evasão é um tema bastante discutido, pois se apresenta como um fenômeno em direção oposta à ampliação das possibilidades de formação e às demandas do mundo do trabalho. Segundo Tigrinho (2008), a evasão no ensino superior brasileiro é um fenômeno grave que acontece tanto nas instituições públicas quantoprivadas, e demanda medidas eficazes de intervenção. Autores que abordam o tema apontam o conhecimento prévio a respeito do curso e a adequada orientação profissional como elementos importantes para evitar sua ocorrência. (SILVA FILHO, 2007; TIGRINHO, 2008). 
Cursos e profissões: conhecendo possibilidades para a escolha profissional

Segundo Tigrinho (2008), ao analisar a evolução do número de ingressantes nos últimos anos, observa-se que a matrícula tem aumentado significativamente, mas não tem garantido a frequência do estudante até o final do curso. Dentre as causas da evasão listadas pelo autor, encontra-se a orientação vocacional/profissional, neste âmbito caracterizada pela falta de informações sobre a profissão e o curso em que os alunos ingressam. Assim, acredita-se que se o sujeito estiver munido de informações acerca dos cursos e profissões, poderá fazer escolhas mais conscientes, o que resultará em maior satisfação com o curso e com a profissão escolhida e na redução dos índices de evasão.

Tendo em vista os aspectos abordados, o presente artigo tem o propósito de apresentar reflexões sobre um projeto de extensão que objetivou fornecer,a estudantes concluintes do Ensino Médio das escolas públicas de um município do norte do Rio Grande do Sul, informações sobre a instituição e os cursos ofertados no Campus, visando auxiliar no processo de escolha profissional e objetivando reduzir os índices de evasão relacionados à falta de conhecimento a respeito do curso escolhido.

\section{MATERIAIS E MÉTODOS}

O projeto de extensão foi realizado em um Instituto Federal de Educação, Ciência e Tecnologia localizado no norte do Rio Grande do Sul. A instituição iniciou suas atividades educativas em 2009, oferecendo cursos técnicos na modalidade subsequente ao Ensino Médio nas áreas de Mecânica, Agroindústria, Vendas e Vestuário. Atualmente são ofertados os cursos técnicos em Alimentos, Finanças, Logística, Mecânica, Vestuário e Modelagem do Vestuário; e os cursos superiores de Engenharia de Alimentos, Engenharia Mecânica, Tecnologia em Design de Moda e Tecnologia em Marketing.

A ação foi organizada e conduzida pela Coordenação de Assistência Estudantil do Campus e executada por uma equipe composta por funcionários técnico-administrativos e docentes da instituição. Assim, o projeto objetivou oportunizar, aos estudantes das escolas públicas do município, reflexões sobre as escolhas profissionais por meio de informações sobre os cursos oferecidos.

Inicialmente, realizou-se contato com todas as escolas da rede estadual de ensino do município, para verificação de interesse de participação e agendamento das atividades. Posteriormenteao agendamento foi estabelecido um cronograma de execução. Por sua vez, o 
Cursos e profissões: conhecendo possibilidades para a escolha profissional

deslocamento dos estudantes foi realizado com o micro-ônibus da instituição, sendo que um servidor do Campus acompanhou os estudantes no trajeto. Solicitou-se, também, a vinda de, pelo menos, um professor de cada escola.

As atividades ocorreram nos três turnos, no período compreendido entre os dias 16 e 29 de outubro do ano de 2014. Foram atendidas oito das nove escolas da rede estadual de ensino do município, com a participação de 459 estudantes. A equipe de execução foi composta por 45 servidores, sendo eles docentes e funcionários técnico-administrativos.

A programação foi desenvolvida em dois momentos. O primeiro deles consistiu na visitação pelas dependências do Campus, conduzida por servidor membro da equipe do projeto. A visitação ocorreu conforme roteiro preestabelecido, com enfoque na estrutura disponível para cada curso, com vistas a ampliar o conhecimento acerca das atividades relacionadas aos cursos e áreas de atuação.

O segundo momento consistiu na realização de palestras sobre a instituição, cursos e possibilidades relativas às carreiras profissionais. Nessas palestras, inicialmente foram feitas breves apresentações sobre a instituição, por meio de slidese de um vídeo institucional. Em seguida, docentes das áreas específicas realizaram explanações sobre os cursos, englobando os seguintes itens: perfil do curso, campo de atuação, modalidade, habilitação, carga horária total, duração, turno de funcionamento, regime, periodicidade da oferta, matriz curricular e possibilidades relativas à carreira. Ao final, abriu-se espaço para questionamentos e apresentou-se um vídeo com informações acerca do processo seletivo institucional.

Ao término da atividade, fotografou-se cada turma, sendo que as fotos foram impressas e enviadas a cada escola, juntamente com uma ficha de avaliação da atividade que foi respondida pelos estudantes e professores que os acompanharam. Um questionário de avaliação também foi respondido pelos membros da equipe de execução.

\section{RESULTADOS E ANÁLISES}

O projeto oportunizou espaços para reflexão e qualificação do processo de escolha profissional dos sujeitos participantes, colocando em pauta a oferta de cursos, possibilidades oferecidas pela instituição e perspectivas em relação às carreiras profissionais.

Considerando o total de escolas públicas de Ensino Médio do município, apenas uma optou por não participar do projeto, sendo que, então, oito escolas foram incluídas nas atividades, e 459 estudantes participaram da ação. Em relação ao instrumento de avaliação, do 
Cursos e profissões: conhecendo possibilidades para a escolha profissional

total de participantes, 348 (75,80\%) responderam ao questionário. Também, 13 professores que acompanharam os estudantes responderam a um questionário específico de avaliação, e 25 $(55,55 \%)$ membros da equipe de execução do projeto.

Conforme o Plano Nacional de Extensão Universitária, a prática extensionista é um instrumento incomparável de mudança nas próprias instituições onde se desenvolve e nas sociedadesem que essas instituições estão inseridas. Assim, a abrangência do público atingido demonstra que a ação extensionista realizada pode traduzir o compromisso social da instituição por meio da integração à comunidade, uma vez que os participantes tiveram a oportunidade de conhecer a instituição, as possibilidades de formação ofertadas e, ainda, pensar suas escolhas profissionais a partir das informações específicas sobre os cursos e carreiras que foram disponibilizadas.

Ao responderem o questionário de avaliação, a maioria dos estudantes, 239 (68,68\%) afirmou que não conhecia a instituição; já do total de professores, 12 (92,31\%) afirmaram que não a conheciam. Estes dados demonstram que a instituição ainda não é suficientemente conhecida localmente, demandando ações que promovam uma maior aproximação com a comunidade, sendo isto fundamental para o cumprimento de seus objetivos e sua função social.

Adentrando na questão das escolhas profissionais, os participantes foram questionados a respeito da contribuição da atividade para sua escolha. Assim, 240 estudantes (68,97\%), responderam afirmativamente. Dentre os motivos relacionados à resposta, destaca-se a ampliação de informações sobre os cursos, que inclui o esclarecimento de dúvidas, o detalhamento de informações e a explanação sobre a estrutura dos cursos e áreas de atuação, como ilustram as falas dos estudantes:

\footnotetext{
Mostrou mea realidade da profissão. (P33)

Contribuiu porque me deixou com a certeza de que é isso que eu quero. (P21)

Explicou o que veremos, então descobrimos se é mesmo o curso desejado. (P69)

Contribuiu porque mostrou como funciona o local de aprendizado e como é após a formação. (P50)
}

Para os participantes, a atividade também contribuiu com a escolha profissional, pois apresentou novas possibilidades e perspectivas de formação, como pode ser observado nos excertos abaixo:

Pude conhecer novos campos e ofertas de cursos. (P22)

Pois pude ter uma melhor compreensão de como ingressar na rede de ensino federal. (P30) 
Cursos e profissões: conhecendo possibilidades para a escolha profissional

Porque descobri novos cursos e como eles funcionam. (P31)

Por outro lado, os estudantes que responderam que a atividade não contribuiu para a sua escolha profissional, afirmaram que isto ocorreu em função de já terem feito a escolha ou pelo fato de a instituição não ofertar o curso desejado, como pode ser observado nas respostas dos participantes P19 e P32, transcritas a seguir:

Achei a atividade muito boa, mas já havia feito a minha escolha. (P19)

Já tenho o que quero para minha vida profissional em mente desde o fundamental (Letras). (P32)

Como é possível observar, as atividades realizadas trouxeram informações relevantes para a escolha profissional de uma parcela significativa dos participantes. Além dos aspectos específicos referentes aos cursos e profissões, a atividade possibilitou o conhecimento de oportunidades de formação até então desconhecidas por alguns estudantes.

Esse desconhecimento pode ser explicado pela recente expansão na oferta de educação pública no país. De acordo com o Ministério da Educação e Cultura (2015), a segunda metade do século XX foi marcada por uma expansão sem precedentes da demanda e da oferta de cursos de educação superior, ligadas tanto à valorização do saber acadêmico pelo mercado de trabalho quanto ao crescimento da importância da pesquisa acadêmica. Desse modo, a criação de novas instituições públicas, a expansão dos cursos e das vagas oferecidas, tem contribuído de modo considerável para o aumento da oferta de educação superior no país, especialmente na última década, quando foram implantados cursos superiores em regiões historicamente desassistidas pela educação pública, promovendo maior democratização do acesso. Assim, a criação de estratégias que promovam maior aproximação com a comunidade é um elemento primordial para que os sujeitos conheçam e apropriem-se das oportunidades de formação disponíveis a partir da expansão da educação técnica e superior.

Ademais, para o estudante, a tarefa de escolher uma profissão fica ainda mais complexa com o aumento das possibilidades de qualificação e atuação profissional. Nesta perspectiva, Neiva (2014) aponta a necessidade da aquisição de conbecimentos e atitudes para que o jovem atinja maturidade para a decisão profissional. A dimensão das atitudes compreende os elementos determinação e responsabilidade para a escolha profissional, bem como a independência na definição da escolha; já a dimensão dos conhecimentos envolve o autoconhecimento e o conbecimento da realidade educativa e socioprofissional(NEIVA, 2003; 2014). 
Cursos e profissões: conhecendo possibilidades para a escolha profissional

No que se refere às concepções de escolha, Ferreti (1988) esclarece que existem escolhas e não escolhas, defendendo que "as opções, quaisquer que sejam, não ocorrem num contexto de plena liberdade” (p.142). O autor apresenta a noção de graus de liberdade, que variam conforme determinantes como idade, sexo, disponibilidade de informação, herança familiar e aquelas decorrentes da classe, normas e costumes vigentes no ambienteem que está inserido o indivíduo. Ainda neste sentido, Vilela (2003) afirma que a escolha consciente é um aspecto fundamental nas trajetórias profissionais, pois pode contribuir para que, ao longo de sua formação, o sujeito tenha melhores condições de desenvolver mais adequadamente as habilidades e competências integrantes de um perfil profissional que possibilite atender com maior efetividade às demandas do mercado e da sociedade. Pode ainda trazer a realização profissional e assim facilitar a autorrealização.

Ao serem indagados sobre o interesse em cursos ofertados pela instituição, 187 estudantes $(53,74 \%)$ responderam positivamente. Destes, 34,76\% afirmaram que não possuíam este interesse antes de participar da atividade. A partir desta informação, pode-se afirmar que a ação realizada foi efetiva no sentido de disponibilizar informações sobre os cursos, além de apresentar possibilidades de formação.

Os estudantes também foram questionados quanto à atividade ter correspondido ou não às suas expectativas. Assim, 314 estudantes (90,23\%) responderam afirmativamente. Os motivos apresentados para a atividade ter correspondido às expectativas dizem respeito à ampliação do conhecimento sobre os cursos, auxílio na escolha profissional, possibilidades apresentadas, qualidade das explicações, esclarecimento de dúvidas, aprendizado obtido, boa recepção e estrutura disponível na instituição. As falas transcritas abaixo ilustram fatores que, para os estudantes, fizeram com que as atividades correspondessem às suas expectativas.

Correspondeu porque tive a oportunidade de conhecer com profundidade os cursos. (P12)

Tive uma visão mais real do que eu gostaria de cursar. (P55)

Possibilitou-me conhecer cursos que não conhecia. (P90)

Não imaginava que o Campus era tão grande e tem muitas oportunidades além do que pensei. (P31)

Jáos estudantes que não tiveram suas expectativas correspondidas, elencaram como motivos o fato de a oferta de cursos não despertar interesse para sua formação profissional e por considerarem a atividade extensa ou cansativa.

Por fim, solicitou-se aos estudantes que avaliassem as atividades por meio dos conceitos muito bom, bom, regular e ruim. Assim, 53,74\% dos estudantes consideraram a atividade muito 
Cursos e profissões: conhecendo possibilidades para a escolha profissional

boa; $40,52 \%$ boa; 3,74\% regular; 1,44\% ruim; e 0,57\% não responderam a questão. Em seguida, os estudantes apresentaram sugestões sobre a metodologia utilizada para o desenvolvimento das atividades e citaram cursos de seu interesse.

Tendo em vista as respostas dos estudantes, depreende-se que as atividades desenvolvidas foram ao encontro dos objetivos propostos, correspondendo às expectativas de um número significativo de participantes,os quais avaliaram que a atividade forneceu informações relevantes sobre os cursos e profissões e, assim, auxiliaram nas escolhas profissionais.

Os professores que acompanharam os estudantes nas atividades, em sua maioria, 84,62\% (11), as avaliaram com o conceito "muito bom", enquanto 15,38\% (2) avaliaram com o conceito "bom". Ao serem questionados quanto à contribuição da atividade para a escolha profissional dos estudantes, todas as respostas foram afirmativas. A pertinência e organização das atividades também foram avaliadas positivamente por todos os docentes, como exemplificado nas falas abaixo:

\footnotetext{
Foi uma oportunidade para conhecer o Campus e os cursos ministrados. E algumas escolhas podem surgir a partir disso. (D1)

Excelente, parte teórica e visitação para despertar o aluno a fazer parte deste ambiente; (D5)

Ótima, pois foi apresentada uma ideia bastante esclarecedora do que cada curso oferece e possibilita. (D11)
}

Destaca-se o fato de que apenas um dos docentes afirmou que conhecia o Campus antes de participar da atividade. Este dado demonstra a necessidade de ações que tornem a instituição conhecida na comunidade em que está inserida, especialmente em contextos educativos, que configuram canais importantes de disseminação de oportunidades de formação.

Os professores também sugeriram a participação dos estudantes no projeto desde o primeiro ano do Ensino Médio. Esta sugestão foi justificada pelo entendimento de que o contato com as informações fornecidas oportunizaria o conhecimento de possibilidades de formação, profissões e carreiras ainda neste período, contribuindo de modo mais eficazpara as escolhas profissionais.

$\mathrm{Na}$ definição da escolha profissional, a exploração de si mesmo e do ambiente são fundamentais para a tomada de decisão. Assim, entende-se a decisão de carreira como a capacidade que a pessoa tem de identificar seus interesses dentro de certa profissão, traçando objetivos profissionais, estratégias e planosque se quer alcançar (TEIXEIRA; GOMES, 2005). Desse modo, a participação em atividades que possibilitem a exploração e a autorreflexão desde o 
início do Ensino Médio facilitaria o processo de escolha profissional. Nesse sentido, avalia-se que a sugestão apresentada deve ser considerada em futuras edições do projeto.

Como mencionado, os servidores envolvidos na atividade também tiveram a oportunidade de responder a um questionário avaliativo sobre as diferentes etapas de execução do projeto. A partir das respostas ao questionário, verificou-se que predominaram avaliações positivas quanto à relevância e pertinência da realização da ação. Da mesma forma, a metodologia utilizada para a execução das atividades foi avaliada de forma positiva. Além disso, foram apresentadas diversas sugestões para futuras edições do projeto.

No processo de execução da ação, e por meio da análise das avaliações da equipe executora, foram identificados fatores que dificultaram o desenvolvimento das atividades. Nesse sentido, um dos principais problemas encontrados foi a escassez de tempo para maior aprofundamento e exploração das atividades.

Tendo em vista a programação e os recursos disponíveis para a ação, as atividades tornaram-se interdependentes, o que exigiu da equipe executora sincronia, organização e comunicação eficaz. Assim sendo, avalia-se que o engajamento da equipe possibilitou que as atividades fossem desenvolvidas sem intercorrências. Desse modo, a equipe de execução avaliou positivamente o engajamento dos membros, os resultados obtidos, e a interação com a comunidade, como ilustram as falas a seguir:

\footnotetext{
A organização e o planejamento das ações foram muito positivas, pois a definição de detalhes contribuiu de forma incisiva no resultado final do projeto. Também foi possível observar o engajamento de vários servidores, o que qualificou a execução do projeto. (S7)

Os alunos das escolas puderam conhecer melhor a instituição, e por mais que não houvesse o interesse pelos cursos ofertados, com certeza adquiriram novos conhecimentos e informações a serem repassadas a outras pessoas de seu convívio ou não, disseminando assim novas possibilidades e oportunidades. (S20)

Equipe envolvida no trabalho realizou atividades integradas. Projeto muito importante para o Campus, pois envolve atividade de extensão proporcionando conhecimento entre cursos oferecidos, assim como campo de trabalho, atendendo dessa forma a comunidade. (S18)
}

Ao serem solicitados a descrever pontos positivos referentes ao desenvolvimento do projeto, os servidores destacaram a interação com a comunidade, a divulgação institucional, o trabalho em equipe e a organização das atividades. Por outro lado, os servidores descreveram como pontos negativos a escassez de tempo para o desenvolvimento das etapas previstas, o não cumprimento do tempo estipulado na condução de algumas palestras sobre os cursos e, ainda, o número reduzido de servidores envolvidos. 
Cursos e profissões: conhecendo possibilidades para a escolha profissional

Por fim, a equipe executora elencou sugestões para próximas edições do projeto. Dentre elas, a inclusão de escolas dos demais municípios da região, a realização de oficinas pelos cursos e a organização de mostras com trabalhos desenvolvidos pelos estudantes. Além disso, todos os servidores afirmaram que a atividade deve ser replicada.

\section{CONSIDERAÇÕES FINAIS}

Acompanhando a demanda por qualificação profissional posta pelo mundo do trabalho atual, verifica-se a expansão da oferta de educação pública, inclusive em regiões historicamente desassistidas, promovendo maior democratização do acesso. Assim, a expansão e a interiorização do ensino trazem outros desafios, pois há um novo cenário que se instaura, trazendo diferentes atores e estruturas.

Um dos desafios que se coloca neste cenário é aproximação com a comunidade, elemento primordial para que os sujeitos conheçam e se apropriem das oportunidades de formação disponíveis. Por outro lado, mesmo os estudantes que chegam até a instituição por vezes apresentam dificuldades pelo desconhecimento dos cursos, o que acaba resultando em evasão.

Tendo em vista o exposto, o projeto de extensão realizado objetivou fornecer, aos estudantes concluintes do Ensino Médio das escolas públicas de um município da região norte do Rio Grande do Sul, informações sobre a instituição e os cursos ofertados em uma instituição da rede federal de educação técnica, científica e tecnológica, visando a auxiliar no processo de escolha profissional dos participantes e reduzir os índices de evasão relacionados à falta de conhecimento do curso escolhido.

A partir da análise do público atingido e das informações obtidas por meio dos questionários de avaliação, é possível depreender que houve a interação esperada entre a instituição e a comunidade. Ademais, as respostas dos participantes remetem ao alcance dos objetivos propostos.

Conforme aponta a literatura (FERRETI, 1998; CARVALHO, 1995; VILELA, 2003), a disponibilidade de informações sobre cursos e profissões é um dos principais elementos que contribuem para uma escolha profissional acertada. Assim, entende-se que a ação foi relevante, uma vez que, por meio da disponibilização de informações sobre cursos e profissões, foi possível auxiliar no processo de escolha profissional de estudantes de Ensino Médio das escolas públicas do município, fato que pode ser constatado por meio do instrumento de avaliação da atividade. 
Cursos e profissões: conhecendo possibilidades para a escolha profissional

Acredita-se que as ações desenvolvidas promoveram maior conhecimento local da instituição e possibilitaram maior congruência entre as concepções e expectativas dos estudantes e a realidade dos cursos ofertados. Espera-se, com isso, favorecer escolhas mais conscientes e, consequentemente, maior adequação e satisfação com o curso e com a profissão escolhida.

Com efeito, a ação potencializou a integração entre a instituição e a comunidade, constituindo-se em uma estratégia que contribuirá com a efetivação dos seus objetivos e função social. Ações desta natureza, ao ampliarem o conhecimento das possibilidades oferecidas pela instituição, revelam seu comprometimento com a realidade na qual está inserida e possibilitam a democratização do conhecimento.

Tendo em vista os resultados obtidos, pretende-se replicar a proposta, considerando as devidas adequações. Uma das dificuldades apontadas pela equipe executora foi a escassez de tempo para o desenvolvimento das atividades previstas, o que exige modificar a metodologia utilizada, prevendo um número menor de participantes em cada etapa. Ainda, a inclusão de escolas dos demais municípios da região e a possibilidade de participação de estudantes desde o primeiro ano do Ensino Médio, além de outras adequações metodológicas sugeridas, são aspectos relevantes a serem considerados. Consequentemente, surge a necessidade de revisão do período de realização e duração das atividades, bem como da participação de um número maior de servidores na equipe de execução.

Considerando os aspectos descritos, é possível analisar que o projeto atingiu o público esperado e aproximou-se dos objetivos propostos. Entretanto, acredita-se que algumas adequações são necessárias para que, nas próximas edições, seja possível ampliar a abrangência das ações desenvolvidas.

\section{REFERÊNCIAS}

ALVES, E.; VIEIRA, C. A. Qualificação profissional: uma proposta de política pública. Planejamento e Políticas Públicas, n. 12, p. 117-146, jun./dez. 1995. Disponível em: <http://www.ipea.gov.br/ppp/index.php/PPP/article/viewFile/143/145>. Acesso em: 15 set. 2014.

BRASIL. Lei n¹1.892/08, de 29 de dezembro de 2008. Institui a Rede Federal de Educação Profissional, Científica e Tecnológica, cria os Institutos Federais de Educação, Ciência e Tecnologia, e dá outras providências. 2008. Disponível em: <http://www.planalto.gov.br/ccivil_03/_ato2007-2010/2008/lei/111892.htm>. Acesso em: 28 set. 2014. 
Cursos e profissões: conhecendo possibilidades para a escolha profissional

CAMPOS, A.; AMORIN, R.; POCHMANN, M. Demanda e perfil dos trabalhadores formais no Brasil em 2007. Brasília: IPEA, 2007. Disponível em:

<http://www.ipea.gov.br/portal/images/stories/PDFs/comunicado/071119_comunicadoipea0 3.pdf>. Acesso em: 16 set. 2014.

CARVALHO, M. M. M. J. Orientação profissional em grupo: teoria e técnica. São Paulo: Editorial Psy, 1995.

FERRETI, C. J. Opção, trabalho: trajetórias ocupacionais de trabalhadores das classes subalternas. São Paulo: Autores Associados, 1988.

FRIGOTTO, G. Educação e Crise do Trabalho: perspectivas de final de século. Petrópolis: Vozes, 1998.

INSTITUTO FEDERAL DE EDUCAÇÃO, CIÊNCIA E TECNOLOGIA DO RIO

GRANDE DO SUL. PPI:Projeto Pedagógico Institucional. Bento Gonçalves, 2011. Disponível em:

<http://www.erechim.ifrs.edu.br/site/midias/arquivos/201227145617602projeto_pedagogico_i nstitucional.pdf>. Acesso em: 28 set. 2014.

JORNADA, M.; SOBRINHO, G. X.; STEMBERG, S. S. Escolaridade do Trabalhador Formal no RS: evolução em um quadro de diversidades regionais. Indicadores Econômicos FEE, v. 28, n. 3, 2000.

LASSANCE, M. C. P. Técnicas para o trabalho de orientação profissional em grupo. Porto Alegre: UFRGS, 1999.

MANFREDI, S. M. Trabalho, qualificação e competência profissional - das dimensões conceituais e políticas. Educação \& Sociedade, Campinas, n. 64, p. 13-49, set. 1999.

MEC. Ministério da Educação. A democratização e expansão da educação superior no país 2003 - 2014. Brasília, 2015. Disponível em: http://portal.mec.gov.br/index.php? option $=$ com_docman\&view $=$ download\&alias $=16762$-balanco-social-sesu-20032014\&Itemid=30192. Acesso em: 04 nov. 2015.

NEIVA, K. M. C. A maturidade para a escolha profissional: uma comparação entre alunos do ensino médio. Revista Brasileira de Orientação Profissional, v. 4, n. 1/2, p. 97-103, 2003.

NEIVA, K. M. C. Escala de Maturidade para a Escolha Profissional (EMEP): Estudo de validade e fidedignidade. Revista Unib, v. 6, p. 43-61, 1998.

NEIVA, K. M. C. Escala de Maturidade para a Escolha Profissional- EMEP. 2. ed. São Paulo: Vetor Editora, 2014.

NERI, M. C. A Educação Profissional e Você. Rio de Janeiro: FGV/CPS, 2010. Disponível em: <http://www.cps.fgv.br/ibrecps/VOT2/index.htm>. Acesso em: 10 set. 2014. 
Cursos e profissões: conhecendo possibilidades para a escolha profissional

REDE NACIONAL DE EXTENSÃO. Plano Nacional de Extensão Universitária. [200-]. Disponível em: < http://www.renex.org.br/documentos/Colecao-Extensao-Universitaria/01Plano-Nacional-Extensao/Plano-nacional-de-extensao-universitaria-editado.pd $>$. Acesso em: 11 nov. 2014.

SILVA FILHO, R. L. L. et al. A Evasão no Ensino Superior Brasileiro. Cadernos de Pesquisa, São Paulo, v. 37, n. 132, set./dez. 2007.

TEIXEIRA, M. A.; GOMES, W. B. Decisão de carreira entre estudantes em fim de curso Universitário. Psicologia: Teoria e Pesquisa, v. 21, n. 3, p. 327-334, set./dez. 2005.

TIGRINHO, L. M. V. Evasão Escolar nas Instituições de Ensino Superior. Revista Gestão Universitária, v. 173, p. 01-14, 2008.

VILELA, E. C. Significado do Trabalho e Escolha acadêmico-profissional: um estudo com universitários primeiranistas.2003. 157 f.Dissertação (Mestrado em Educação) - Programa de Pós-Graduação em Psicologia, Universidade Federal do Rio Grande do Norte, Natal, 2003. 